\title{
Robert Szymula
}

Uniwersytet w Białymstoku

\section{ЛИНГВИСТИЧЕСКИЕ ОСОБЕННОСТИ ПРОГРАММНОЙ РЕЧИ ПРЕЗИДЕНТА \\ (НА ПРИМЕРЕ ПОСЛАНИЯ ФЕДЕРАЛЬНОМУ СОБРАНИЮ)}

\author{
SUMMARY \\ Linguistic features of the programme speach (exemplified by the message \\ to the Federal Assembly)
}

The political discourse is a complex linguistic phenomenon which attracts attention of many scientists from different fields, which shows its interdisciplinary character. The message to the Federal Assembly is one of the important types of modern Russian political discourse. It is a relatively new genre in Russia (first message to the Federal Aseembly was delivered in 1994). The aim of the message is to inform members of the Parliament and citizens of Russia about the situation in the country and outline the plan of the development.

The material for the research was President Putin's message from 2002. The author analyzed the composition of the speech, its topics and linguistic features.

Key words: discourse, political discourse, programme speech, political linguistics, president's message, socio-cultural differences

\section{STRESZCZENIE}

Cechy lingwistyczne przemówienia programowego (na przykładzie przesłania do Zgromadzenia Federalnego)

Dyskurs polityczny stanowi złożone zjawisko językowe, które przyciąga uwagę wielu badaczy z różnych dziedzin nauki, co wyraźnie wskazuje na jego interdyscyplinarny charakter. Jednym 
z ważnych gatunków współczesnego rosyjskiego dyskursu politycznego jest przesłanie do Zgromadzenia Federalnego. Jest to stosunkowo nowy dla Rosji gatunek (pierwsze przesłanie zostało wygłoszone w 1994 r.). Jego celem jest poinformowanie członków Parlamentu i obywateli Rosji o sytuacji w kraju oraz nakreślenie kierunków rozwoju.

Materiał do danego badania stanowiły przesłania prezydenta Putina z jego pierwszej kadencji (ze szczególnym uwzględnieniem wystąpienia z 2002 r., które posłużyło jako źródło przykładów). Analizie poddano kompozycję wystąpienia, jego tematykę i cechy językowe.

Политический дискурс является объектом пристального внимания многих исследователей. Интерес к данной области усиливается обычно в связи с изменениями в политической и общественной жизни, как это имело место, например, в случае русского политического дискурса. Помимо существования многих опубликованных работ по этой тематике, все-таки ряд вопросов является предметом дискуссий.

Так как политическим дискурсом интересуются представители разных областей науки, его исследование нуждается, несомненно, в междисциплинарном подходе. Междисциплинарность исследований обусловливает анализ политического дискурса с разных точек зрения: филологической (политический текст рассматривается как обычный текст, однако на фоне политических и идеологических концепций), политологической (политологическая интерпретация), социопсихолингвистической (измерение эффективности достижения целей говорящего), индивидуальногерменевтической (интерпретация политического дискурса в определенных обстоятельствах $)^{1}$.

Среди методов анализа, использованных лингвистами при анализе политического дискурса, выделяются критическое, дескриптивное и когнитивное направления ${ }^{2}$. Ученые, предпочитающие критический подход (например, Водак, Дейк), утверждают, что политический дискурс - это неотъемлемая часть общественных отношений, которая рассматривается как использование языка, как вхождение в общественное сознание определенных представлений и как взаимодействие социальных групп и индивидов. Данный подход направлен на изучение социального неравенства, выраженного в языке или дискурсе (например, проблема использова-

1 В. 3. Демьянков, Политический дискурс как предмет политологической филологии, [w:] Политическая наука. Политический дискурс: история и современные исследования, Москва 2002, s. 34.

2 Е. И. Шейгал, Семиотика политического дискурса, Волгоград 2000, s. 7-8. 
ния языка как средства власти и социального контроля). Дескриптивный подход имеет свои корни в классической методике риторического анализа публичных речей. В рамках данного подхода изучаются языковые средства, риторические приемы и манипуляторские стратегии, используемые политиками, а также анализируется содержательная сторона политических текстов. Сторонники когнитивного подхода исследуют политический дискурс при помощи анализа фреймов, концептов и метафорических моделей. Данный подход позволяет перейти от описания единиц и структур дискурса к моделированию структур сознания участников политической коммуникации.

Как показывают исследования многих ученых, до сих пор не выработана общепринятая дефиниция понятия „политический дискурс”. Это, наверное, связано с объективными трудностями, вызванными сложностью и многоаспектностью самого объекта, неодинаковым пониманием границ и состава общественно-политической лексики, спецификой обозначаемых явлений.

Политический дискурс в узком понимании - это „текст, обусловленный ситуацией политического общения”, „совокупность всех речевых актов, используемых в политических дискуссиях, а также правил публичной политики, освещенных традицией и проверенных опытом” ${ }^{4}$. При широком подходе политический дискурс включает в себя „любые речевые образования, субъект, адресат или содержание которых относится к сфере политики".

Кроме неоднозначности самого понятия „политического дискурса”, следует заметить, что нет также однозначного ответа на вопрос о том, какие речевые жанры включаются в данную сферу. Наиболее системную типологию жанров политического дискурса представляет Е. И. Шейгал, которая разделяет жанры этого вида дискурса в зависимости от ряда параметров

1) дифференциация по степени институциональности:

- разговоры о политике в семье, с друзьями, разговоры с незнакомыми людьми в очереди, со случайными попутчиками и т.д., анекдоты, слухи;

- самиздатовские листовки и граффити;

- телеграммы и письма граждан в знак поддержки или протеста;

- политический скандал;

3 Е. А. Попова, Культурно-языковые характеристики политического дискурса (на материале газетных интервъю). Автореф. дис. ... канд. филол. наук, Волгоград 1995, s. 5.

4 А. Н. Баранов, Е. Г. Казакевич, Парламентские дебаты: традиции и новаиии, Москва 1991, s. 6.

5 Е. И. Шейгал, Семиотика..., s. 23.

6 Ibidem, s. 307-325. 
- пресс-конференции;

- публичные политические дискуссии;

- публичные выступления, речи политических лидеров;

- законы, указы и прочие политические документы;

- международные переговоры, официальные встречи руководителей государств;

2) дифференциация по субъектно-адресным отношениям:

- жанры, характерные для общественно-институциональной коммуникации: постановления правительства, декреты, законы, призывы, лозунги, плакаты, публичная речь, радиообращение, указ президента;

- жанры, характерные для коммуникации между институтом и гражданином: петиции, обращения, листовки, наказы избирателей, выступления на митингах, телеграммы и письма граждан, обращенные к политикам и институтам непосредственно или через масс-медиа;

- жанры, характерные для коммуникации между агентами в институтах: служебная переписка, кулуарное обсуждение, закрытое заседание, переговоры, встречи политических деятелей, парламентские дискуссии, круглый стол, послание Президента Конгрессу, выступление премьер-министра на заседании Думы, доклад на съезде, партийная программа, программная речь на съезде партии);

3) социокультурная дифференциация:

- политические социолекты, основанные на идеологической ориентации, образованные как эффект неоднородности групповых субъектов политики.

Дифференциальными признаками разных политических социолектов являются: специфический набор парольных лозунговых слов, отражающих ценностные доминанты данной группы; различия в характере вербальной агрессии (степень косвенности и предпочитаемый набор инвектив); разный удельный вес речевых стереотипов и штампов; разный удельный вес эмотивно-маркированной лексики (в частности, полярные различия в оценочных коннотациях политических антропонимов); специфический набор цитат, аллюзий и прочих отсылок к прецедентным текстам, отражающим ценностные предпочтения той или иной группы.

4) дифференциация по событийной локализации:

- дифференциация, основанная на разделении событий политической жизни на ритуальные (выборы и предшествующая им предвыборная кампания, церемония инаугурации, завершающая 
очередной выборный цикл; очередные съезды партии, церемонии патриотических праздников, ежегодное выступление Президента с посланием Федеральному Собранию), календарные (встречи депутатов с избирателями, парламентские слушания, визиты политических деятелей, переговоры) и спонтанные (митинги, пикеты и демонстрации, политические кампании (протеста или поддержки), акции гражданского неповиновения, политические скандалы, референдумы).

Следует отметить, что в большинстве случаев коммуникативные политические события являются сложными и включают несколько речевых жанров (например, встречи депутатов с избирателями связаны с такими жанрами, как объявление, выступление депутата, ответы на вопросы, наказы избирателей), существуют также жанры, непосредственно не являющиеся составной частью конкретного события, например, граффити.

5) дифференциация по степени прототипности-маргинальности:

- прототипные жанры: парламентские дебаты, публичная речь политика, лозунг;

- периферийные жанры: интервью, мемуары политиков, аналитические статьи, письма читателей, разговоры о политике, смеховые жанры.

Ученая дифференцирует также жанры политического дискурса по характеру ведущей интенции, выделяя:

- ритуальные жанры (инаугурационная речь, юбилейная речь, традиционное радиообращение);

- ориентационные жанры (партийная программа, манифест, конституция, послание президента о положении в стране, отчетный доклад, указ, соглашение);

- агональные жанры (лозунг, рекламная речь, предвыборные дебаты, парламентские дебаты).

Одним из важных жанров политического дискурса в России, интересных с лингвистической точки зрения, является послание Федеральному Собранию Российской Федерации. Послание Федеральному Собранию - это большое программное выступление Президента, играющее важную роль в жанровой системе современного русского президентского дискурса. Согласно классификации, предложенной Е. И. Шейгал, оно принадлежит к ритуальным жанрам политического дискурса ${ }^{7}$. Необходимость ежегодного обращения Президента к Федеральному Собранию предусмотрена Конституцией (согласно пункту «е» статьи 84 Президент Российской Федерации „обращается к Федеральному Собранию с ежегодными посланиями о поло-

7 Ibidem. 
жении в стране, об основных направлениях внутренней и внешней политики государства" 8 ). Данный документ определяет оценку ситуации в стране и позицию главы государства по основным направлениям государственной политики, заявленные им приоритеты по вопросам внутренней политики учитываются парламентом и правительством при составлении планов законопроектных работ и указывают влияние на формирование общественного мнения. Как отмечает А. Ильин, „программные выступления - это всегда событие огромной важности как в карьере лидера, так и в политической жизни страны. Как он охарактеризует нынешнее положение страны, какие решения проблем предложит, что намерен предпринять сейчас и каковы его дальнейшие планы - ответов на эти вопросы от политика с надеждой ждут его сторонники и с опаской - его противники. От того, что скажет и что будет делать лидер, напрямую зависит развитие политического процесса"9.

Послание Федеральному Собранию - это относительно новый жанр в русском политическом дискурсе. Первым посланием российского Президента является послание „Об укреплении Российского государства. Основные направления внутренней и внешней политики", с которым выступил Президент России Б. Н. Ельцин 24.02.1994 г. Оно было произнесено вскоре после принятия новой Конституции Российской Федерации, главной его темой было становление правового государства, необходимость соблюдения Конституции и законов, защита прав граждан, проведение рыночной реформы в стране. Следующие послания Президента Ельцина - это „О действенности государственной власти в России” из 16.02.1995 г., „Россия, за которую мы в ответе” из 23.02.1996 г., „Порядок во власти порядок в стране” из 6.03.1997 г., „Общими усилиями - к подъему России” из 17.02.1998 г. и „Россия на рубеже эпох” из 30.03.1999 г. Очередные послания принадлежат Президентам В. В. Путину и Д. А. Медведеву. Материалом для нашего исследования послужили тексты посланий В. В. Путина из первого периода его правления. В качестве примера выбрано послание Президента В. В. Путина 2002 года ${ }^{10}$.

Выбранное для данного анализа послание Федеральному Собранию было произнесено Президентом В. В. Путиным 18.04.2002 г. в Мраморном зале Кремля. Непосредственными участниками события были депутаты Государственной думы, члены Совета Федерации, руководители регионов.

8 http://www.constitution.ru/10003000/10003000-6.htm [dostęp: 15.10.2013].

9 А. Ильин, В. Ф. Кабацкий, К. В. Никифоров, Л. Г. Пихоя, Отзвук слова. Из опыта работы спичрайтеров первого президента России, Москва 1999, s. 6.

10 http://archive.kremlin.ru/appears/2002/04/18/0001_type63372type63374type82634_28876.shtml, [dostęp: 15.10.2013]. 
Оно транслировалось в прямом эфире по каналу государственного телевидения и на государственной радиостанции.

Анализ текста послания выявил, что оно состоит из следующих структурных частей: приветствие, обращение, вступительная часть, основная часть, заключение и благодарность за внимание. Сопоставление с другими посланиями В. В. Путина позволяет утверждать, что такая структура является характерной для данного дискурсивного типа.

Послание начинается с приветствия и обращения к аудитории. Послание из 18.04.2002 г. обращено только к представителям законодательной власти. В других посланиях В. В. Путина выступает обращение ко всем гражданам России.

Во вступительной части Президент представляет цели данного политического события („Мы вновь собрались в этом зале, чтобы подвести итоги за год и поставить задачи на предстоящий период"11), описывает стратегические направления развития страны („Наши цели неизменны - демократическое развитие России, становление цивилизованного рынка и правового государства. И самое главное - повышение уровня жизни нашего народа”), подводит итоги за прошлый год („В прошлом году продолжился экономический рост. (...) Люди уверенно смотрят в завтрашний день (...) постепенно улучшается деловой климат в стране”), выражает неудовлетворение результатами („Однако следует признать и другое: политическая стабильность и благоприятная экономическая конъюнктура не использованы в полной мере для качественного улучшения жизни граждан страны, для завоевания Россией достойного места в мировой экономической системе”).

Описывая успехи, В. В. Путин использует речевые средства как прямого (цифровые данные), так и опосредованного информирования (метафорические модели роста и движения: „продолжался экономический рост”, „доходы граждан выросли”, „продвижение в развитии инфраструктуры рынка”, „мы сделали существенный шаг в модернизации судебно-правовой системы”, строительная метафора „многие начинают строить долгосрочные личные планы”, „предприниматели строят свои планы уже в расчете не на месяцы, а на годы”).

Следует заметить, что выражая неудовлетворение результатами, Президент использует языковые средства, смягчающие категоричность критики: „непростая задача”, „непомерное бремя”, „неопределенность, за что именно должны отвечать государственные органы”, „нечеткость в разграничении полномочий”.

11 Все цитаты из текста послания: http://archive.kremlin.ru/appears/2002/04/18/0001_type63372type63374type82634_28876.shtml [dostęp: 15.10.2013]. 
Основная часть послания - это презентация внутренней и внешней политики России. Данная часть текста имеет свою микроструктуру, информация излагается по условному плану: описание сегодняшней ситуации (трудностей), причины трудностей, желаемый результат, задачи на будущее.

Описывая цели, стоящие перед Россией, Президент часто использует предикаты („нельзя”, „должен”, „надо”, „необходимо”) и соответствующие синтаксические конструкции („для + отглагольное существительное в родительном падеже”, „для этого + глагол со значением необходимости", придаточные предложения с союзом „чтобы”). Следует подчеркнуть, что В. В. Путин, определяя задачи, не указывает конкретных лиц, ответственных за их реализацию. Адресатом сообщения или объектом действий является просто „правительство”. Описанию международного положения России в посланиях В. В. Путина отводится обычно немного места (в послании из 2000 г. эта тематика вовсе отсутствовала).

В заключительной части Президент выражает уверенность в реализации поставленных задач. В этой части выступления В. В. Путин удачно использует анафору - повторение сходных звуков, слова или группы слов в начале каждого параллельного ряда („Чтобы жить в ней комфортно и безопасно. Чтобы люди могли свободно трудиться, без ограничений и страха зарабатывать для себя и для своих детей. И чтобы они стремились ехать в Россию, а не из нее. Воспитывать здесь своих детей, строить здесь свой дом"), которое передает риторический напор и подчеркивает чувство уверенности.

Завершая выступление, Президент благодарит аудиторию за внимание („Спасибо вам за внимание”).

Темы, которые затрагивает В. В. Путин в своем выступлении, - это: экономическое ускорение, проблемы малого бизнеса, вступление в ВТО, административная реформа, судебная реформа, реформа ЖКХ, местное самоуправление, федеративное устройство, наука, военная реформа, борьба с терроризмом, реформа правовой системы, взаимодействие со странами СНГ, реформа естественных монополий, положение в Чечне, преступность, перепись населения, управление государственной собственностью, борьба с коррупцией, здравоохранение, стратегическая стабильность, банкротство предприятий, банковская реформа, интеграция с Европой.

Отбор тем для послания осуществляется, наверное, на основе значимости данного топика в системе политических представлений В. В. Путина. Основная тема выступления - это политические задачи, которые Президент ставит перед Правительством и гражданами на предстоящий год. Во всех своих посланиях В. В. Путин уделяет основное внимание задачи улучшения экономической ситуации России, что вызвано, как можно предполагать, 
требованиями как внутренней, так и внешней политики. Преемственность тематики выступлений подчеркивают элементы типа: „год назад мы ставили скромную, но чрезвычайно важную задачу”, „в прошлогоднем Послании я ставил задачу”, „год назад с этой трибуны я говорил”, „об этом я уже говорил с самого начала", отсылающие слушающих к предыдущим выступлениям.

Анализируя структуру послания, следует остановиться на некоторых ее композиционных особенностях. В. В. Путин использует разного рода языковые средства, которые облегчают выделение значимой информации. При введении новой темы, Президент использует формулы типа: „отдельно остановлюсь на...”, „что касается...”, „еще один важный вопрос...”, „еще одна важная тема.... Каждый топик внутри построен логично, с четкой организацией материала, что подчеркивает перечисление: „первое..., „второе..., „во-первых...”, „во-вторых...”, „в-третьих...”, „в завершении.... Следующим приемом, который помогает слушающим отделить один топик от другого, является постановка самого важного в смысловом отношении предложения в начале абзаца, что ускоряет и уточняет восприятие содержания текста. Похожую функцию выполняют обращения к слушающим („Уважаемые коллеги!”, „Уважаемое Собрание!”), которые, кроме привлечения внимания, выделяют также части высказывания.

Главной задачей, которая стоит перед Правительством, Президент определил экономическое развитие. В связи с этим текст выступления насыщен словами экономического содержания (экономическими терминами): „экономика”, „малый бизнес”, „конкуренция”, „потребители продукции и услуг”, „инфраструктура рынка”, „естественные монополии” и т.п. В послании много терминов из области финансов: „налоговая система”, „дефицитный бюджет”, „кредитный рейтинг”, „финансовый контроль”, „финансовые ресурсы”, „процентные ставки”, „инвестиционные программы”, „капитализация”, „ипотечное кредитование” и т.п. Очень употребительны словосочетания с прилагательными „экономический” („экономическая жизнь страны”, „экономический рост”, „экономическая конъюнктура”, „экономическая задача”, „экономическая политика”, „экономический режим”, „экономическая ситуация”, „экономическое влияние” и т.п.), „деловой” ( „деловой партнер”, „деловая активность”, „деловой климат”) и „предпринимательский” („предпринимательская активность”, „предпринимательская среда").

Экономическая направленность содержания выступления подчеркивается также стилистически, при помощи использования некоторых приемов, характерных для деловой коммуникации. В. В. Путин часто вводит в текст обороты из канцелярского стиля („за счет развития малого бизнеса”, „исходя 
из наших возможностей”, „на базе использования тех норм”, „по результатам эксперимента”, „при наличии реальных действий”, „с учетом интересов наших партнеров” и т.п.), описательные обороты типа: „исполнить принятые решения”, „давать соответствующее поручение”, „привести в соответствие”, „принять соответствующее решение” и т.п., характерные для деловых документов сложные формы сравнительной степени прилагательных („более высокие темпы роста”, „более быстрые темпы”), конструкции „необходимо + инфинитив”, „нужно + инфинитив”, использование страдательного залога (пассивные конструкции).

Заметное место в послании В. В. Путина из 2002 г. занимает также тема правовой реформы (этот слоган присутствует во всех посланиях В. В. Путина). Отражением значимости данной проблемы является частое использование в выступлении юридической терминологии („налоговый кодекс”, „законодательные акты”, „правовая система”, „судебная система”, „судебная практика”, „уголовное законодательство”, „арбитражные суды”, „законодательная база” и т.п.).

Характерной чертой послания В. В. Путина является также довольно высокая частотнось слов иноязычного происхождения. Примером может служить частое использование существительных на -ация, образованных от глаголов с иноязычной основой („консервация”, „модернизация”, „интеграция”, „коммерциализация”, „конфронтация”, „реструктуризация”, „интернационализация”, „дебюрократизация” и т.п.). В послании встречаются также прилагательные и глаголы иноязычного происхождения („комплексный”, „эффективный”, „легитимный”, „интегрироваться”, „стимулировать”, „дискредитировать”, „аккумулировать”, „адаптироваться”, „оптимизировать” и т.п.). Следует подчеркнуть, что у многих слов иноязычного происхождения, выступавших в тексте послания, есть свои русские эквиваленты („консенсус” - „согласие”, „конфронтация” - „противостояние” и т.п.). Использование иноязычной лексики является характерной чертой современного русского политического дискурса. Можно предполагать, что в случае послания Федеральному Собранию это явление может быть вызвано, хотя бы частично, стремлением придать выступлению черты высокого стиля. Однако, следует заметить, что это может затруднять полное понимание текста слушающими, так как во многих случаях в сознании слушающих с иноязычным словом не ассоциируется конкретный образ, особенно в случае, если данное слово не вошло еще полностью в активный состав языка.

В анализируемом послании обращает на себя внимание также большое количество слов с отвлеченным значением (обобщенное действие, безличное действие). Это, в первую очередь, существительные мужского рода 
с нулевым суффиксом („рост”, „учет”, „переход”, „подход”, „надзор”, „спор” и т.п.), образованные от глаголов, которые чаще всего называют действие безотносительно к действительности и характеру его протекания. Следующие группы - это существительные типа pluralia tantum с отвлеченным значением („переговоры”, „расходы” и т.п.), существительные с отвлеченным значением признака или свойства, образованные от имен прилагательных с помощью суффикса -ость („нечеткость”, „ясность”, „жизнеспособность”, „доступность”, „необходимость”, „особенность”, „прозрачность” и т.п.) и образованные от глаголов с помощью суффикса -ность („продуманность”, „проработанность”), отглагольные существительные со значением отвлеченного процессуального действия с суффиксом -ение („проведение”, „привлечение”, „наведение”, „разграничение” и т.п.), обобщенные субстантивированные прилагательные и причастия, отвлеченные от конкретных явлений и предметов („многие”, „другие”, „достигнутое” и т.п.).

Анализируя синтаксические особенности текста выступления, можно отметить, что послание состоит из 172 абзацев. Наиболее частотными являются абзацы, состоящие из 2-4 предложений (43 абзаца состоит из одного предложения, в том числе 14 - это этикетные формулы, 48 абзацев - из двух предложений, 40 абзацев - из 3 предложений, 37 - из 4 предложений, 11 абзацев - из 5 предложений, 2 абзаца - из 6 преждолений и 1 абзац - из 7 предложений). Такое построение выступления, наверное, способствует лучшему восприятию информации. Важной чертой текста является постороение абзацев по определенному принципу. Обычно основную информацию содержит первый абзац текста, далее президент представляет ситуацию, затем описывает желаемый эффект и в конце указывает на меры, которые надо предпринять, чтобы добиться данной цели. Нередко один тематический блок составляет один абзац.

Добавочным элементом, который помогает в лучшем понимании содержания послания, является, наверное, построение предложений - в выступлении преобладают простые предложения (в тексте 433 предложения, только 124 из них - сложные). Этот прием может, однако, создавать ощущение некоторой фрагментарности описания.

Интересным является анализ синтаксической структуры предложений, входящих в состав послания. По мнению М. В. Гавриловой, выбор определенных грамматических форм является значимым, так как позволяет выявить идеологические установки политика ${ }^{12}$. Следует заметить, что в исследуемом послании Президент при описании ситуации, сложившейся к настоящему

12 М. В. Гаврилова, Критический дискурс-анализ в современной зарубежной тингвистике, Санкт-Петербург 2003, s. 12. 
моменту, или описывая задачи, стоящие перед Россией в будущем, использует пассивный залог. Данный прием позволяет Президенту не помещать действующие лица в позиции субъекта и не сосредотачивать внимание на агентах политических действий, ответственных за сложившуюся ситуацию и реализацию планов. Данной цели служит также частое использование безличных предложений, построенных по схеме „предикатив + инфинитив”, в которых главный член предложения называет процесс или состояние, независимо от действующего лица, что является особенно странным при описании планов на будущее и перспектив развития России (неизвестно кто, когда, где, как, что именно будет делать для реализации намеченных задач). Похожее ощущение вызывает большое число отглагольных существительных, использованных вместо глаголов, так как данные существительные лишены категории времени, вида, залога и поэтому производят впечатление неопределенности. Глагольные формы выступают в послании довольно редко (только 42\% всех предложений выступления содержит глагольную форму), что влияет на отсутствие динамизма выступления (следует заметить, что это характерная черта официально-делового стиля). Другими приемами построения текста, которые вызывают ощущение его статичности, является большое число безличных предложений (их главный член называет состояние или процесс) и предложений со значением „субъект - его наличие или отсутсвие".

Несомненно, в случае послания очень важным элементом является аргументативная стратегия - яыковые средства, которые Президент использует при подаче информации, чтобы убедить аудиторию, влиять на нее и воздействовать на ее поведение. С одной стороны, аргументативная стратегия Президента должна соответствовать ожиданиям слушающих, с другой, должна быть направлена в некоторой степени на их переубеждение (не только информирует об общеизвестных явлениях, но также подвергает их сомнению и иногда отвергает). Анализируя текст послания из 2002 г. следует отметить, что В. В. Путин в большинтсве случаев поддерживает только аудиторию в том, в чем она уже убеждена, пытается укрепить ее мнение. Для того, чтобы доказать свои суждения и подтвердить их объективность, Президент нередко использует цифровые данные („Реальные доходы граждан выросли почти на 6 процентов”, „Численность безработных сократилась на 700 тысяч человек”). В. В. Путин пытается создать ощущение аргументированности суждений и логичности изложения также при помощи вводных слов, управляющих процессом восприятия текста („во-первых”, „во-вторых”, „в-третьих”, „далее”, „наконец”), что кроме того помогает остановить внимание аудитории на самых важных аргументах и распределяет аргументы по степени важности. 
Одной из важных задач Президента в случае послания (большой по объему речи) является установление и поддержание контакта со слушающими, а также сближение с ними. Языковыми средствами, которые в этом помогают, являются:

- использование притяжательного местоимения „наш” („наша экономическая политика");

- использование личных местоимений 1 лица единственного и множественного числа („я прошу Федеральное Собрание”, „мы своевременно (...) обслуживаем внешний долг”);

- использование глагольных форм 1 лица („давайте вспомним о норме");

- использование конструкций, состоящих из вопросительного предложения и ответа на него („Удовлетворяет ли нас достигнутое? Наш ответ - конечно же, нет, еще раз нет”);

- использование конструкций с вводными словами, выражающими личную оценку представленной информации („полагаю..., „думаю, что...”, „очевидно, что...”);

- использование обращения к знаниям слушающих („как вы знаете”).

Для поддержания внимания аудитории Президент пытается также придать своему выступлению выразительность и наглядность изложения. Одним из средств, которые этому служат, является использование метафор и других риторических приемов.

В современном политическом дискурсе наблюдается высокая частотность метафор. Метафора правратилась в одно из наиболее сильных средств представления политических концепций и воздействия на политическое сознание общества. Ученые выделяют следующие функции политической метафоры ${ }^{13}$ :

- когнитивная функция - метафора понимается как основная ментальная операция, способ познания и категоризации мира, при помощи метафоры соответствующее явление политики подводится под категорию, что позволяет лучше определить сущность этого явления и выразить свое отношение к нему;

- коммуникативная функция - метафора понимается как средство передачи информации и во многих случаях позволяет передавать информацию в более удобной для адресата форме (разновидностью коммуникативной функции можно считать эвфемистическое ис-

13 А. П. Чудинов, Политическая лингвистика, Москва 2006, s. 81-85. 
пользование метафор - метафора позволяет передать информацию, которую автор по разным причинам не считает целесообразным обозначить прямо, при помощи непосредственной номинации);

- прагматическая функция - метафора понимается как способ изменения политических воззрений адресата, побуждения его к определенным действиям, воздействия на эмоционально-волевую сферу адресата и формирования у него соответствующего отношения к рассматриваемым реалиям;

- эстетическая функция - метафора понимается как способ привлечения внимания адресата и придания высказыванию действенности (хорошо подобранная метафора может восприниматься как признак глубины и смысловой точности).

Продуктивными метафорами, которые можно заметить в тексте послания В. В. Путина (кроме упомянутых уже выше метафорических моделей роста и движения и строительной метафоры), являются метафоры войны. Президент, говоря о развитии экономики, использует глаголы „бороться”, „захватить”, „враждовать”. Военную метафорическую модель встречаем, когда описывается путь России к преобразованию экономической системы: „(..) для завоевания Россией достойного места в мировой экономической системе”, „Однако хочу обратить внимание и на другое: нормой в международном сообществе, современном мире является и жесткая конкуренция - за рынки, за инвестиции, за политическое и экономическое влияние. И в борьбе, этой борьбе, России надо быть сильной и конкурентоспособной”. Е. О. Опарина замечает, что метафора войны, указывающая на конкуренцию в мире политики и экономики, формирует представление о серьезности ситуации и акцентирует концепт „вызов” ${ }^{14}$. Метафора войны является также продуктивной, когда политики обращают внимание аудитории на противостояние „свои - чужие” (например, во время предвыборной кампании).

Следующей продуктивной метафорической моделью является метафора персонификации. По мнению Баранова и Казакевич ${ }^{15}$, с помощью метафоры персонификации множатся политические субъекты. Персонификация в политическом дискурсе позволяет человеку осваивать мир, дает более широкий спектр альтернатив принятий решений. Власть и государственные органы представлены в послании как живой человек („на плечи

14 Е. О. Опарина, Метафора в политическом дискурсе, „Политическая наука. Политический дискурс: история и современные исследования", Москва 2002, nr 3, s. 29.

15 А. Н. Баранов, Е. Г. Казакевич, Парламентские дебать: традиции и новаиии, Москва 1991, s. 31 . 
парламента ложится большая работа”, „федеральная власть практически не уделяла внимания проблемам местного самоуправления”, „власть порождает законы”, „бессмысленное соревнование между народом и властью”). Наименования разных государственных органов выступают в функции субъекта предложения, т.е. как активно действующие личности („правительство”, „ведомства”, „госорганы”, „судебные и правоохранительные органы”, „правоохранительные органы”, „милиция и прокуратура”, „федеральная власть”, „государственные органы”, „государственная власть”).

Риторической особенностью, использованной в тексте послания очень часто, является выделение слов или словосочетаний в кавычки („Надо установить своего рода «мораторий» на проверки для малых предприятий”; „Кампанейщины, которая обычно заканчивается плавным «переливом» чиновников из одной структуры в другую”; „(...) разграничение полномочий произошло лишь «на бумаге»”; „(...) заключать такие договоры «за спиной» других субъектов Федерации”; „Федеральное Собрание должно «на ясном глазу» принимать это решение”; „(..) перечень вопросов «местного значения»”; „Наша страна все еще «выключена» из процесса формирования правил мировой торговли”; „Заплатил за справку - и «гори себе на здоровье»”; „В этой связи продуманная «архитектура» нашего участия в ВТО должна состоять из нескольких элементов” и т.п.). Данный прием, наверно, является экспрессивным средством выражения иронии - кавычки указывают на слова, использованные в ироническом смысле, а не в в основном значении („даже самые «благие намерения» разработчиков не должны становиться поводом для правовой небрежности”; „Хочу обратить внимание, что «аккуратное» отношение государства к этим монополиям, к сожалению, уже используется ими для поднятия тарифов”). В некоторых случаях кавычки указывают на авторские выражения и метафоры („Для граждан он еще остается «черным ящиком»”, „(...) поддержать или не поддержать усилия по уничтожению его «логова»”, „ «Поточное» банкротство предприятий уже успело стать доходным бизнесом"). Их использование выделяет также из текста устоявшиеся идиоматические обороты („начинающему бизнесу крайне важна возможность «встать на ноги»”; „очень многие в мире поняли, что «холодная война» закончилась”; „Для «головокружения от успехов» нет никаких оснований”; „заключать такие договоры «за спиной» других субъектов Федерации”), часто трансформированные („За место под «экономическим солнцем» нам нужно бороться самим”; „мир распахнет нам свои «экономические объятия»”; „страховая компания будет «отвечать рублем»”; „Между тем непродуманные либо недоработанные проекты часто ставят наше предпринимательство не «на ноги», а «на уши»"). В некоторых случаях данный прием придает нейтральным словам эмоционально-экспрессивную 
окраску („Ведомства по вполне понятным причинам «цепляются» и будут «цепляться» за эти функции”; „(...) тысячи коммерческих организаций, «кормящихся» на проверках").

Для усиления выразительности речи Президент часто использует повтор слов („Работа со странами СНГ - главный внешнеполитический приоритет России. Приоритет, связанный в том числе с получением конкурентных преимуществ на мировых рынках”; „После 11 сентября прошлого года многие, очень многие в мире поняли, что «холодная война» закончилась. Поняли, что сейчас - другие угрозы, идет другая война - война с международным терроризмом”; „Мы строим со всеми государствами мира - хочу это подчеркнуть: со всеми государствами мира - конструктивные, нормальные отношения”; „Кроме того, именно здесь, на местном уровне есть огромный ресурс общественного контроля за властью. И на этом уровне мы обязаны навести порядок. Тот порядок, о дефиците которого говорят и пишут граждане страны”) и повторяющиеся союзы („Это нужно и для развития гражданского общества, и для формирования цивилизованной предпринимательской среды”; „Значительная часть предприятий практически не вкладывает средств ни в создание новых технологий, ни в модернизацию старых"). Этот прием усиливает коммуникативное воздействие речи, улучшает понимание текста, позволяет логически и интонационно выделить самые важные элементы отрывков текста. Выделение важной информации реализуется также другими языковыми средствами. Предидент употребляет слова и выражения типа: „обратить внимание”, „подчеркнуть”, „отметить”, указательные местоимения, наречия степени („очень”, „крайне”), соединительные союзы с противительной связью („не только..., но и...”, „не столько..., сколько...”), инверсию (важные логически элементы поставлены на первый план), паузы в речи и тире на письме.

Послание Федеральному Собранию, относительно новый в России ритуальный жанр, является важным элементом русского политического дискурса. Его главная функция - это функция сообщения. Оно является преимущественно информационным текстом. Эмоционально-оценочная лексика составляет незначительное количество слов в анализируемом выступлении, в нем содержатся в большинстве сведения о предмете сообщения, субъекте и объекте деятельности, результатах деятельности субъекта, пространственных и временных факторах деятельности. Основной интенцией послания является информирование аудитории, разъяснение целей и основных приоритетов развития России, оценка ситуации в различных сферах общественной жизни, представление основных направлений политики государства. Другая интенция послания - призыв к действию - не выражена так сильно и направлена в большинстве к представителям государ- 
ственной власти, не к гражданам. Послание выполняет также убеждающую функцию (Президент убеждает аудиторию, влияет на нее и воздействует на ее поведение).

Структура выступления имеет устойчивый характер (приветствие, обращение, вступительная часть, основная часть, заключение и благодарность за внимание). Основная тема послания - это политическая задача, которую ставит Президент представителям государственной власти на предстоящий год. Приоритетной задачей является экономический рост. В. В. Путин сосредотачивает внимание на внутренней политике, внешней политике не отводится много места. Передача информации организована согласно общему регулирующему принципу: переход от сегодняшних трудностей через причины к желаемому результату и задачам по улучшению ситуации.

Президент использует различные приемы, способствующие выделению значимой информации (такие как использование слов типа: „подчеркнуть”, „обратить внимание”, „отметить”, „только”, „именно”, речевые формулы для введения новой темы, указательные местоимения, наречия степени, использование обращений для разграничение тем, разбиение материала внутри топика по порядку перечисления, выделение паузами в речи и тире на письме, соединительные союзы с противительной связью, начальная позиция ключевой фразы в абзаце, инверсия, паузы и другие). В. В. Путин пользуется также различными приемами, облегчающими понимание речи (повторы, структурирование информации, небольшая длина предложения и т.д.). Заслуживает внимания частое употребление иностранных слов, слов с отвлеченным значением и профессиональной (экономической и юридической) лексики, что, на наш взгляд, может затруднять понимание текста широкой аудиторией.

Несомненно, чертой посланий В. В. Путина, которая обращает на себя внимание, является своего рода разрыв между главными функциями текста (сообщение и убеждение) и ощущением неконкретности при представлении планов на будущее (неизветсно кто, когда, где, как, что именно будет делать для реализации поставленных задач). Заслуживает внимания также факт, что тема внешней политики не является важной в посланиях В. В. Путина (Президент представляет Федеральному Собранию и гражданам в большинстве только рекомендации, касающиеся внутренней политики). 